\title{
Early marriage in South Wollo and East Gojjam zones of the Amhara Region, Ethiopia
}

\author{
Kerebih Asrese, Mulunesh Abebe \\ Bahir Dar University, Faculty of Social Sciences, Bahir Dar, Ethiopia \\ Email address: \\ Kerebih2000@yahoo.com (K. Asrese)
}

To cite this article:

Kerebih Asrese, Mulunesh Abebe. Early Marriage in South Wollo and East Gojjam Zones of the Amhara Region, Ethiopia. Humanities and Social Sciences. Vol. 2, No. 2, 2014, pp. 11-16. doi: 10.11648/j.hss.20140202.11

\begin{abstract}
Early marriage has profound physical, intellectual, psychological and emotional impacts and reduces educational opportunities and the chance for personal growth for both boys and girls. This study investigated the prevalence of early marriage in South Wollo and East Gojjam zones of the Amhara Region in Ethiopia. Data were collected from 769 respondents (476 females and 293 males) who were randomly selected from two zones. Structured questionnaires, focus groups and in-depth interviews were used for data collection. Percentages and Chi-square were used for analysis. The results revealed that early marriage is prevalent in the study areas. Its incidence was higher in East Gojjam(87\%) than South Wollo( $80 \%)$ and much higher for females $(83 \%)$ than males (17\%). Early marriage experience across age cohorts shows a revival of the practice. Hence, legal campaigns against early marriage that allow full community participation are recommended.
\end{abstract}

Keywords: Early Marriage, South Wollo, East Gojjam, Amhara Region, Ethiopia

\section{Introduction}

Though birth, marriage and death are the standard key events in most people's lives, marriage is a matter of choice The right to exercise that choice is recognized as a principle of law and has long been established in international human rights instruments [1]. However, many girls and a smaller number of boys enter marriage without exercising their right to choose. Some girls are forced into marriage at a very early age. Others are too young to make an informed decision about their marriage partner or about implications of marriage. They may accept the consent made by others on their behalf $[1,2]$.

The practice of early marriage is most common in South Asia, Sub-Saharan Africa and Latin America and the Caribbean, where $48 \%, 42 \%$, and $29 \%$ of women respectively, aged 15-24 marry before the age of 18 . In the Middle East, North Africa and other parts of Asia, marriage at or shortly after puberty is common among those having traditional lifestyles. Marriages earlier than puberty are also usual in specific parts of West and East Africa and South Asia $[2,3]$.

As in most developing countries, early marriage is prevalent in Ethiopia. The 2000 Ethiopian DHS further reveals that $31 \%$ of women aged $25-49$ years were married before age 15 and $70 \%$ of women in the same age group were married before age 18 . The median age at first marriage in the same year was 16 years [4]. The 2005 Ethiopian DHS also maintains similar trends. The report shows that, nationwide, close to $44 \%$ women aged $25-49$ were married before age 15 and $66 \%$ were married before age 18. In 2005, the median age at first marriage was 16.1 years [5].

The Amhara region of Ethiopia has one of the highest rates of early marriage in the country. In the region, the median ages at first marriage for women in the age group $25-49$ were 14.3 years in 2000 [4] and 14.2 years in 2005 [5]. Pathfinder International reported that in the Amhara Region, $48 \%$ of women married before age 15 , and $82 \%$ married before age 18 , and the median age at first marriage was 14years [6].The National Committee on Traditional Practices of Ethiopia also reported that in a sample in Amhara region, $88 \%$ of girls were married before age 15 and $37 \%$ before they were 10 years old [2].

Early marriage has profound physical, intellectual, psychological and emotional impacts and reduces educational opportunities and the chance for personal growth for both boys and girls. For girls, in addition, it brings premature pregnancy and childbearing [6]. Early marriage also has implications for the well-being of society 
as a whole. When girls are uneducated and less-prepared for their roles as mothers and contributors to society, there are costs for the individual household and the society as a whole $[1,7]$.

Early marriage compromise women's reproductive health as well. Early pregnancy and childbearing are commonly associated with fistula (a condition when women are unable to withhold urine and/or feces). This condition results when birth occurs before the growth of the pelvis is complete $[8,9]$. Due to its association with early sexual activity and childbearing, early marriage also has implications for children's health. Infants of teenage mothers are more likely to suffer from low birth-weight and to die compared with infants of mothers who delayed childbearing [6].

Owing to the high prevalence of early marriage and its associated consequences in Ethiopia, governmental and non-governmental organizations (GOs and NGOS) have been working to end its practice. The legal base for fighting early marriage practices has been put in place in Ethiopia with the adoption of the Revised Family Law, the new Penal Code and other legal instruments since 2000 [10]. Though the judiciary system already deals with a significant number of cases related to early marriage and is highly involved in legal literacy training of civil society groups, the knowledge of the extent and context of early marriage in the Amhara Region is still inconsistent [11].

Therefore, this study investigated early marriage in South Wollo and East Gojjam zones of Ethiopia where its incidence is highly prevalent. It explored the knowledge and attitudes of residents towards early marriage practice. The study was expected to provide recent evidence on the early marriage practice in the two zones so that appropriate interventions can be pursued.

\section{Method}

A multi-purpose cross-sectional household survey was carried out in East Gojjam and South Wollo zones of the Amhara Region. The two zones have 33 rural districts (17 districts in South Wollo and 16 districts in East Gojjam) and three urban centers. Six rural districts (three from each zone) were randomly selected and the three urban centers were included in the study.

Multistage stratified random sampling by administrative divisions was used to select study divisions and households. From each selected district and urban center, two kebeles (the lowest administrative unit in the government administrative structure) were randomly selected. The selected kebeles were then divided into sub-kebeles and a sub-kebele was randomly selected from each kebele. Lists of the households in the selected sub-kebeles were obtained from the kebele administrative offices and served as a sampling frame to select the participants for the study. Systematic random sampling was used to select individual study participants. Marital experience (currently married or ever married) and age were used as inclusion criteria. A total of 769 respondents, of which 476 women and 293 men aged 15 and above were selected for the study. To increase the representativeness of the information, ten additional districts which were not included in the household survey (five districts from each zone) were randomly selected and included in the study.

Structured questionnaires, focus groups and in-depth interviews were used to collect the data. Both the structured questionnaires and interview guides were pilot-tested. Based on the pilot results, some items were modified, some were discarded, and some new items were added before final administration. Structured questionnaires were used to collect quantitative data. The questionnaires were prepared separately for women and men. The items in the questionnaires were developed in English and translated into Amharic to ease communication between interviewers and respondents. FGD guides and in-depth interview guides were used to collect qualitative information.

Nineteen FGDs (one FGD in each district and in each urban center) with an average of 9 participants in each FGD were conducted in the two zones. The participants of the FGDs were representatives of women's associations, youth, girls' clubs, teachers, anti-harmful traditional practices committee, gender analysts, and local officials. In addition, 19 in-depth interviews were held with individuals selected purposefully for the study. In- depth interviews were held on an individual basis. The participants in the interview were judiciary personnel, health professionals, community elders, religious leaders, representatives of district women affairs bureaus, and victims of early marriage. The how, when, where, by whom and why of early marriage as well as other underlying factors were discussion points. The qualitative data were tape recorded, transcribed, and organized using open, axial, selective coding, and thematic coding techniques [12] for analysis.

\section{Results}

Information on age at first marriage was obtained by asking all ever-married respondents their age at which the marriage contract was made between them and their first spouse by themselves or by another responsible person on their behalf. Marriage below the age of 18 is considered as early marriage as of the Revised Family Law of the Amhara Region.

Early marriage is highly prevalent in the two zones included in the study. Its incidence is higher for females than males. About $83 \%$ of females and about $17 \%$ of males had early marriage experience. Early marriage practice is higher in East Gojjam than South Wollo (87\% versus $80 \%$ ). In East Gojjam, $65 \%$ of female respondents had their first marriage below age 15 and $87 \%$ had their first marriage below age 18. In South Wollo the proportion of female respondents with age at first marriage below 15 years was $36 \%$ and those who first married before age 18 was about $80 \%$ (Table 1). 
Table 1. Percentage of Respondents whose Age at First Marriage is Lower than the Specified Ages at First Marriage by Gender and Zone

\begin{tabular}{|c|c|c|c|}
\hline \multirow{2}{*}{ Gender } & \multirow{2}{*}{ Zone } & \multicolumn{2}{|c|}{ Age at first marriage } \\
\hline & & $\%<15$ years & $\%<18$ years \\
\hline \multirow{3}{*}{ Females } & South Wollo & 35.5 & 79.7 \\
\hline & East Gojjam & 65 & 86.5 \\
\hline & Total & 48.9 & 82.7 \\
\hline \multirow{3}{*}{ Males } & South Wollo & 2.6 & 6.4 \\
\hline & East Gojjam & 8.3 & 17.4 \\
\hline & Total & 5.2 & 16.7 \\
\hline
\end{tabular}

The median age at first marriage for women was also lower in East Gojjam than in South Wollo (12 years versus 15 years). The median age at first marriage for men was 19 years and 22 years in East Gojjam and South Wollo, respectively (Figure 1).

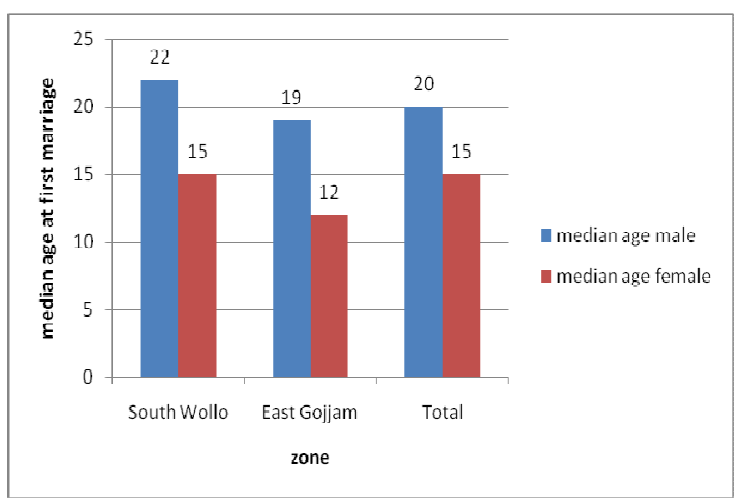

Figure 1. Median Age at First Marriage by Zone

The practice of early marriage was also assessed using the age cohorts to indicate trends in the practice. The prevalence of early marriage among women below ages 15 and 18 is high in the younger and older age cohorts (Table 2).

Table 2. Percentage of Respondents whose age at First Marriage is lower than the Specified Ages by Current Age and Gender

\begin{tabular}{lllll}
\hline $\begin{array}{l}\text { Current } \\
\text { age }\end{array}$ & $\begin{array}{l}\text { Gender } \\
\text { Women } \\
\mathbf{\%}<\mathbf{1 5}\end{array}$ & $\begin{array}{l}\mathbf{\%}<\mathbf{1 8} \\
\text { years }\end{array}$ & $\begin{array}{l}\text { Men } \\
\mathbf{\%}<\mathbf{1 5} \\
\text { years }\end{array}$ & $\begin{array}{l}\mathbf{\%}<\mathbf{1 8} \\
\text { years }\end{array}$ \\
\hline $15-19$ & 59.4 & 90.7 & - & - \\
$20-24$ & 42.1 & 71.9 & - & 66.7 \\
$25-29$ & 38.7 & 67.7 & 20 & 10 \\
$30-34$ & 48.4 & 82.3 & 6.7 & 10 \\
$35-39$ & 48.4 & 86.7 & 6.1 & 15.2 \\
$40-44$ & 53.8 & 90.3 & 4.9 & 9.8 \\
$45-49$ & 44.5 & 83.4 & 7.1 & 14.3 \\
$\geq 50$ & 54.7 & 89.6 & 2.3 & 9.8 \\
Total & 48.9 & 82.7 & 5.2 & 11.5 \\
\hline
\end{tabular}

The median age at first marriage among women for the age group 15-19 and for the age group 50 years and above is 14 years whereas the median age at first marriage for age groups 20-39 is 15 years. The median age at first marriage for men also declined from 20 years for the age group 50 years and above to 17 years for the age group $20-24$ years (Figure 2).

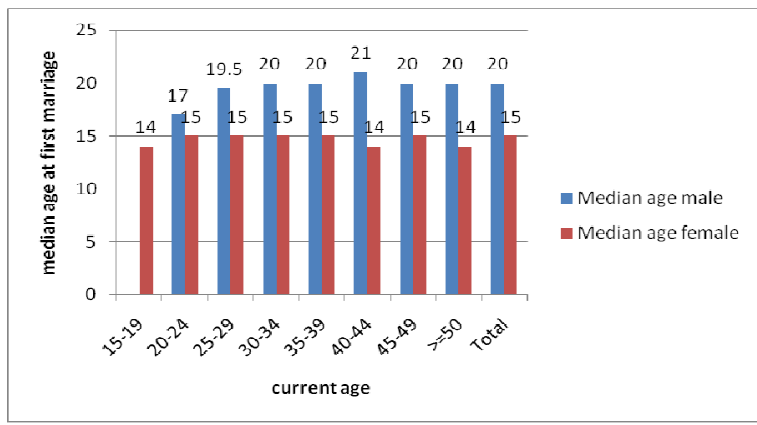

Figure 2. Median Age at First Marriage by Current Age

The FGDs participants and key informants also confirmed that early marriage is commonly practiced in each zone and district though the degree may vary from place to place. They shared that even though measures to prevent early marriage are being taken by the judiciaries, police or other administrative bodies at each level, parents persist in marrying off their daughters at an early age. They marry off their daughters at night in the name of feasts and other traditional ceremonies in many of the districts in the zones. Sometimes parents bring the elder girl for medical age estimation and marry off the younger daughter. Moreover, parents advise their children to report higher ages to the committee that is in charge of marriage approval in the locality.

Respondents who had at least one married daughter mentioned several reasons for early marriage. Conformity to social norms (98\%) and seeking social status (94\%) are the two main reasons for early marriage. Ensuring virginity $(56 \%)$, material benefit $(49 \%)$ and security for the future (about $47 \%$ ) are also factors of early marriage recognized by respondents (Table 3 ).

Table 3. Reasons for Early Marriage

\begin{tabular}{lll}
\hline Reasons & Frequency & Percent \\
\hline Conformity to social norms & 277 & 98.2 \\
Social status & 266 & 94.3 \\
Ensuring virginity & 157 & 55.7 \\
Access for resources & 138 & 49.3 \\
Security for the future & 132 & 46.8 \\
Increasing fertility & 58 & 20.6 \\
\hline
\end{tabular}

In a similar vein, the FGD discussants and key informants in both zones identified various reasons for early marriage. Conformity to social norms, prevention of premarital sex, familial satisfaction, and security for the future were reiterated by the participants. A majority of the discussants emphasized that girls are expected to be virgins at their first marriage. Matured girls might experience premarital sex with or without their consent. This is very outrageous for themselves and the family at large. One of the elderly key informant stated that "virginity of girls at first marriage is a prize for the girls as well as for the families. Early marriage is the most effective way of attaining this social value".

Nevertheless, the majority of respondents (88\%) knew that early marriage is harmful. Awareness about the harmful 
effects of early marriage is higher in South Wollo (91\%) than East Gojjam (83\%). Urban dwellers have significantly greater awareness than their rural counterparts $(95 \%$ versus $84 \%$ ). Respondents with formal education have better awareness (98\%) than those with informal education (89\%) and with no education (78\%). Men have higher awareness about the harmful effects of early marriage than women
(94\% versus about $82 \%$ ). The level of awareness of harmful effects of early marriage is higher for respondents who have exposure to mass media than for respondents without such exposure (92\% versus 79\%). Awareness of the harmful effects of early marriage among religious groups seems similar (Table 4).

Table 4. Knowledge and Attitude of Respondents towards Early Marriage by Background Characteristics

\begin{tabular}{|c|c|c|c|c|c|c|}
\hline $\begin{array}{l}\text { Background } \\
\text { characteristics }\end{array}$ & $\begin{array}{l}\text { Responden } \\
\text { harmful } \\
\text { frequency }\end{array}$ & $\begin{array}{l}\text { at early marriage is } \\
\%\end{array}$ & $\chi^{2}$ & $\begin{array}{l}\text { Responder } \\
\text { early marı } \\
\text { frequency }\end{array}$ & $\begin{array}{l}\text { rt the continuation of } \\
\%\end{array}$ & $x^{2}$ \\
\hline \multicolumn{7}{|l|}{ Zone } \\
\hline South Wollo & 380 & 91.3 & \multirow{3}{*}{$14.46^{*}$} & 27 & 7.1 & \multirow[b]{3}{*}{$8.78 * *$} \\
\hline East Gojjam & 293 & 83 & & 46 & 13.2 & \\
\hline $\begin{array}{l}\text { Total } \\
\text { Residence }\end{array}$ & 673 & 87.5 & & 73 & 9.5 & \\
\hline Rural & 433 & 84.1 & \multirow{2}{*}{$19.48 *$} & 62 & 12 & \multirow{2}{*}{$8.6 * *$} \\
\hline \multicolumn{5}{|l|}{ Gender } & & \\
\hline Women & 389 & 81.7 & \multirow[b]{2}{*}{$37.11 *$} & 66 & 13.9 & \multirow[b]{2}{*}{$21.85^{*}$} \\
\hline $\begin{array}{l}\text { Men } \\
\text { Edu. Status }\end{array}$ & 274 & 93.5 & & 19 & 6.5 & \\
\hline Formal & 279 & 97.6 & \multirow[b]{2}{*}{$63.18^{*}$} & 10 & 3.1 & \multirow[b]{2}{*}{$31.28 *$} \\
\hline $\begin{array}{l}\text { Informal } \\
\text { Illiterate }\end{array}$ & $\begin{array}{l}151 \\
243\end{array}$ & $\begin{array}{l}88.8 \\
77.6\end{array}$ & & $\begin{array}{l}19 \\
56\end{array}$ & $\begin{array}{l}10.0 \\
16.1\end{array}$ & \\
\hline $\begin{array}{l}\text { Exposure to } \\
\text { Mass media }\end{array}$ & \multicolumn{2}{|c|}{ Exposure to } & & & & \\
\hline $\begin{array}{l}\text { Yes } \\
\text { No }\end{array}$ & $\begin{array}{l}450 \\
223\end{array}$ & $\begin{array}{l}92.4 \\
79.3\end{array}$ & $31.74 *$ & $\begin{array}{l}35 \\
41\end{array}$ & $\begin{array}{l}7.2 \\
14.6\end{array}$ & $12.42 *$ \\
\hline \multicolumn{7}{|l|}{ Religion } \\
\hline Orthodox & 413 & 86.8 & \multirow[b]{3}{*}{ n.s. } & 48 & 10 & \multirow[b]{3}{*}{ n.s. } \\
\hline Muslim & 246 & 88.7 & & 29 & 10 & \\
\hline Others & 14 & 94.1 & & 1 & 6.7 & \\
\hline
\end{tabular}

*Significant at $\mathrm{P}<0.000 ; * *$ significant at $\mathrm{P}<0.003$

As indicated in Table 4, support for the continuation of early marriage is higher in East Gojjam (13\%) than South Wollo $(7 \%)$ and in rural areas $(12 \%)$ than urban areas (about 6\%). Women's support for early marriage continuation (14\%) is also higher than men's (7\%). Support for the continuation of early marriage is higher for illiterate respondents $(16 \%)$ than respondents with informal education (10\%) and with formal education (3\%).

Table 5. Harmful consequences of Early Marriage

\begin{tabular}{ll|l}
\hline Consequences of EM & Frequency & Percent \\
\hline Early Pregnancy & 630 & 93.7 \\
School attrition & 632 & 93 \\
Prolonged and obstructed labor & 624 & 92.7 \\
Marital instability (divorce) & 599 & 89.3 \\
Hemorrhage during labor & 597 & 88.7 \\
Death & 593 & 88.1 \\
Abortion & 585 & 86.9 \\
Still birth & 569 & 84.5 \\
Fistula & 493 & 73.3 \\
\hline
\end{tabular}

Respondents who are aware of the harmful effects of early marriage identified a number of harmful effects of early marriage to a varying degree. Early pregnancy (94\%), school attrition (93\%), and prolonged and obstructed labor (93\%) are mentioned as the three top harmful effects of early marriage (Table 5). Similar opinions were given by
FGD discussants and key informants. Divorce, prolonged labor, ill-health, fistula and school attrition were mentioned as harmful consequences of early marriage.

Moreover, participants shared that since girls are married off at the age of 7 or 8 years and even below, they may not have the chance to attend school. Those who have already started learning are forced to interrupt, and many of them never go back to school. Girls who are married and resume school again are not welcome by their peers. Mostly, they become a pointing object to peers. In addition, peers whisper at them and exclude them from games and other activities in school. This may lead married students to various psychological problems like stress, anxiety, and depression. "A previously sociable and expressive student becomes in-expressive, depressed and isolated after her marriage" one teacher shared.

More importantly, health professional discussants underlined the health consequences of early marriage. Early marriage is associated with problems of prolonged and obstructed labor during delivery. Since the birth canal of the young girl will not allow the head of the fetus to pass easily, prolonged labor and death of the fetus in the uterus is observed, especially in remote rural areas where there is a lack of trained assisted delivery. The discussants also pointed out that prolonged labor can damage the birth canal 
that leads to fistula and sometimes death of the mother due to bleeding. Cases of fistula were presented in many discussion sessions as well as by key informants in almost all study areas.

\section{Discussion}

This study examined the prevalence of early marriage as well as the knowledge and attitude of the people towards its practices in East Gojjam and South Wollo zones of the Amhara Region in Ethiopia. Information on age at first marriage was obtained by asking respondents retrospectively their age at which their marriage contract was made between them and their first spouse. Early marriage is highly prevalent in the two zones. The prevalence is higher for women than men. About $49 \%$ of women were married before age 15 and about $83 \%$ were married before age 18 . The result is consistent with previous research reports that indicate $48 \%$ of women married before age 15 and $81 \%$ married by age 18 in the Amhara Region [6]. The 2000 Ethiopian DHS also indicated that about $50 \%$ of girls in the age group 20-24 were married by age 15 and $80 \%$ were married by age 18 in the Amhara Region [4]. But in the age group 20-24, this study showed substantial decline in early marriage practice. The proportions of respondents who married before ages 15 and 18 in the age group $20-24$ were $42 \%$ and $72 \%$, respectively.

Even if trend analysis from age groups in a crosssectional analysis is tentative, the data indicate a $7 \%$ increase in the median age at first marriage for women in the 30 year span between those aged 20-24 and those 50 years and above. However, this shift in early marriage practice seems to fail to maintain the trend. Rather, the practice seems to be reviving for the median age at first marriage for the youngest age cohort (15-19) was 14 years, which was observed before 35 years. Though the median age at first marriage for males is higher than for females, an increasing trend of early marriage practice among males is also observed. Males' median age at first marriage in the age group 20-24 was 17 years, while for the oldest age cohort ( 50 years and above) it was 20 years. This shows that a $17.6 \%$ median age decline for males was observed in the 30 year span between those aged 20-24 and those 50 years and above. One possible reason for this may be the low attention given to early marriage by the government, as suggested by discussants. They argued that during the previous government, there was a committee responsible for approving marriages. Both the bride and the groom were obliged to be observed by the committee for approval. Someone who wedded a bride or groom not approved by the committee was subjected to punishment by the government. This practice was weakened during the power shift between the previous government and the existing administration. Such a practice has begun in an integrated way more recently in the existing government; hence, it may take some time to observe its impact.
Respondents' knowledge of the harmful effects of early marriage and attitudes towards its continuation were inversely related. They have an appreciable level of awareness of the harmful consequences of early marriage. Overall, about $88 \%$ of respondents knew that early marriage is harmful. The results show improvement in the level of awareness of the harmful effects of early marriage compared to the previous findings in the Amhara region $(64.5 \%)$ reported by National Committee on Traditional Practices of Ethiopia [2].

Despite this appreciable level of awareness, early marriage continues to be practiced for various reasons, which are many and mutually reinforcing. Conformity to social norms, for social status, ensuring virginity, access to resources, and security for the future are important reasons given for early marriage. The qualitative analysis was consonant with the quantitative responses. Though there are efforts by both the GOs and NGOs to end early marriage practices, parents persist in marrying off their daughters at an early age.

\section{Conclusion}

This study revealed that early marriage is prevalent in the study areas. Its incidence was higher for females than males. Majority of the respondents knew that early marriage is harmful. However, knowledge alone has not prevented early marriage practices in the study areas. The community keeps on marrying off their children early. Hence, much remains to be accomplished to bring objective behavioral changes. The established legal literacy training against early marriage that allows full community participation should be strengthened. Moreover, a system of vital registration may help to confirm the true age of marriage candidates. Social workers can take an active role in this campaign against early marriage. They can advocate against early marriage and mobilize the community against its practice. Future research that assesses the effectiveness of the methods of interventions in practice is also called for so that alternative approaches to prevent early marriage can be designed.

\section{Strengths and limitations}

In the study, respondents were asked retrospectively their age at their first marriage. Since there is no vital registration system and because of memory lapse, respondents may not know or remember their exact age at their first marriage. In both circumstances, there may be problem of age misreporting. Moreover, in the study setting, people establish social relationship with other family members. Early age at first marriage is a sign of wontedness for both the girl and her family. Conversely, late marriage is a sign of un-wontedness. Thus, respondents may deliberately report lower age at first marriage to show their wontedness in their community.

Even so, the study has strengths. It employed 
quantitative and qualitative approaches to collect data. A community-based survey was undertaken to investigate the prevalence of early marriage in the study setting. This information was supplemented by qualitative evidences that assessed the reasons for early marriage practices and its current status. The study also used data collection instruments pilot tested before final administration. This procedure allowed modifying some of the items included in the questionnaire and in the interview so that respondents and informants could feel comfortable to reply their experiences.

\section{References}

[1] UNICEF. (2001). Early marriage: Child spouses. Innocents Digest, No.7, 1-30.

[2] National Committee on Traditional Practices of Ethiopia. (2003). Ethiopia harmful traditional practices: Old beyond imaginings Addis Ababa.

[3] Pankrust, H. (1992). Gender, development and identity. London: Biddles Ltd.

[4] Central Statistical Authority and ORC Macro. (2001). Ethiopia demographic and health survey 2000. Addis Ababa, Ethiopia and Calverton, Maryland, USA: Central Statistical Authority and ORC Macro.

[5] Central Statistical Agency and ORC Macro .(2006). Ethiopia demographic and health survey 2005. Addis
Ababa, Ethiopia and Calverton, Maryland, USA: Central Statistical Agency and ORC Macro.

[6] Pathfinder International. (2006). Report on causes and consequences of early marriage in Amhara Region, Retrieved September 20, 2008, from $\mathrm{http} / / /$ pathfindorg/site/Docserver/PTE_final_report

[7] Guday, E. (2005). Early marriage and its effects on girls education in rural Ethiopia: The case of Mecha Woreda in West Gojjam, North-Western Ethiopia. Unpublished doctoral dissertation, Goerg-August University of Goettingen, Gottingen.

[8] AFROL. (2006). Gender profiles: Ethiopia. Retrieved December 14, 2007, from http://www.afrol.com/categories/women/profiles/ethipiawo men.htm

[9] Population Council. (2005). Child marriage briefing: Ethiopia. Retrieved April 19, 2008, from http://www.populationcouncil.org/pdfs/briefingsheets/ETHI OPIA.pdf

[10] Teshome, T. (2005). Early marriage in Ethiopia: Law and social reality. Addis Ababa: Ye Ethiopia Goji Limadawi Dirgitoch Aswegaj Mahiber.

[11] Sida-Amhara Rural Development Program Coordination Unit (SARDP-PCU). (2004). Government pillar main summary report, Bahir Dar.

[12] Kreuger, L., \& Neuman, W. (2006). Social work research methods: Qualitative and quantitative applications with research navigator. Boston: Pearson Education. 